\title{
TAHSP:-
}

The Internet Joưnal of Allied Health Sciences and Practice

A Peer Reviewed Publication of the College of Health Care Sciences at Nova Southeastern University

Dedicated to allied health professional practice and education

http://ijahsp.nova.edu Vol. 11 No. 3 ISSN 1540-580X

\section{The Effect of Platelet-Rich Plasma on Elbow Tendinopathies: A Systematic Review}

\author{
Sarah Schwetlik, Musculoskeletal \& Sports Physiotherapist ${ }^{1}$ \\ Luke Strempel, Musculoskeletal \& Sports Physiotherapist ${ }^{2}$
}

1. Physiotherapist, Vital Core Physiotherapy, St. Morris, South Australia

2. Physiotherapist, The Physio Clinic, Prospect, South Australia

Australia

CITATION: Schwetlik S, Strempel L. The Effect of Platelet-Rich Plasma on Elbow Tendinopathies: A Systematic Review. The Internet Journal of Allied Health Sciences and Practice. July 2013. Volume 11 Number 3.

\section{ABSTRACT}

Purpose: Elbow tendinopathies are common conditions that typically last 6 to 24 months. There is no clear consensus in the literature regarding the most effective management. Platelet-rich plasma (PRP) is an autologous blood product used for elbow tendinopathies with the aim of enhancing tissue regeneration. The aim of this systematic review was to evaluate the available evidence on the effectiveness and safety of PRP for reducing pain and physical function in elbow tendinopathies. Methods: Electronic databases were searched for relevant studies and data were extracted regarding the design, sample characteristics, interventions, and outcome measures. Each study was critically appraised for methodological quality using a modified tool for quantitative studies and presented in a narrative summary. Results: The search strategy identified 299 hits related to plateletrich plasma and/or elbow tendinopathies. Five studies met the inclusion criteria; all were randomized controlled trials except one cohort study. All five studies showed improvements from baseline in pain and physical function with a PRP intervention. One study and its follow-up study showed significant improvements in pain and function with PRP compared to corticosteroid at 26 , 52, and 104 weeks. Two studies compared PRP to whole blood, which did not find sufficient evidence to suggest one is more effective than the other. A cohort study found PRP was more effective than placebo at 4 and 8 weeks. Three studies reported on the safety of PRP and found no significant adverse effects. Conclusions: The current literature has some limitations and is insufficient to provide strong recommendations regarding the use of PRP in elbow tendinopathies over other modalities; however, these studies suggest that PRP may be more efficacious than corticosteroid injections, but that whole blood injections may be as effective as PRP.

\section{BACKGROUND}

\section{Description of the Condition}

Elbow tendinopathies, either medial or lateral in location, may be diagnosed as tennis elbow, golfer's elbow, rowing elbow, epicondylitis, epicondylosis, epicondylagia, tendonitis, and tendinosis. ${ }^{1,2}$ For this review, the term "elbow tendinopathies" is used to allow for a greater level of inclusion.

Elbow tendinopathy refers to "a failure of the normal tendon repair mechanism associated with angiofibroblastic degeneration."3 Clinically, elbow tendinopathies often present as an overuse injury or following a change in training, technique, or activity. There is generally local tenderness over the site of the injury and pain with gripping, twisting, and activities that require forearm strength. Walker-Bone and colleagues found the prevalence of lateral epicondylitis in the general population to be $1.3 \%$ and $1.1 \%$ for men and women respectively, while medial epicondylitis had a prevalence of $0.6 \%$ and $1.1 \%$ for men and women 
respectively. ${ }^{4}$ And while most patients will recover within a year, a typical episode lasts between 6 to 24 months, thus, potentially presenting significant costs through medical and pharmaceutical intervention and time off work. ${ }^{5}$

Wide-ranging treatments have been trialed for elbow tendinopathies. Eccentric exercise programs have shown encouraging results but require further and precise research.6,7 NSAIDs have insufficient evidence to support or refute their use. ${ }^{8}$ Low level laser therapy may reduce pain and disability over the short-term, while repetitive shock wave therapy has some evidence under well-defined, restrictive conditions only.9,10 Satisfying results of shock wave therapy in the range of $60 \%$ have been identified with common variables such as chronic recalcitrant patients; weekly intervals of repetitive application of 2000 low-energy shock wave therapy over 3 to 6 weeks; without local anesthesia; and a follow-up of at least 3 months post application. ${ }^{10}$ Acupuncture has shown some short term benefit for pain, and surgery has insufficient evidence to support or refute its effectiveness. ${ }^{1,2}$ While corticosteroid injection was once considered the gold standard, controversy exists regarding negative side-effects of corticosteroid injections on tendons, with a recent systematic review on tendinopathies finding that although there is consistent short-term benefit from corticosteroids, it is worse than other conservative interventions in the long term. ${ }^{11}$

\section{Description of the Intervention}

Platelet-rich plasma (PRP) is an autologous blood product with a higher concentration of platelets than that of whole blood. ${ }^{12}$ The use of platelet concentrates in medicine to improve healing is a relatively recent development, facilitated by an increase in the understanding of their role in inflammation and healing processes. Despite considerable research in the last decade, PRP use and efficacy remains controversial. ${ }^{13}$

In the preparation of PRP, blood is taken and an anticoagulant added, which is then centrifuged immediately to separate the blood into several layers; the desired layer is the "buffy coat" between the red blood cells and platelet-poor plasma, which has a high concentration of platelets. ${ }^{13}$ Although the generic term "PRP" is commonly used, variances in the preparation systems exist, yielding varying end-products. ${ }^{13}$

PRP is purported to enhance tissue regeneration and healing through high quantities of growth factors released by the platelets. ${ }^{12}$ The rationale behind PRP is to reverse the normal proportions of blood such that the quantity of red blood cells is minimized and the quantity of platelets is maximized.

Previous systematic reviews have looked at various injection therapies for tendinopathies as a whole but have found little evidence to support PRP because of paucity of trials, methodological flaws, and inconsistent findings. ${ }^{11,14,15,17}$ Taylor et al reviewed the evidence for the use of PRP for ligaments and tendons of multiple body areas and concluded that the evidence for PRP for soft tissue treatments was weakly supported. ${ }^{16}$ One systematic review has looked at injection therapies (prolotherapy, polidocanol, whole blood, and PRP) for lateral elbow tendinopathies; however, the authors considered only one study that had used platelet-rich plasma and therefore meaningful conclusions could not be drawn. ${ }^{17}$

\section{Why it is Important to do this Review}

With the evident lack of a gold standard treatment for elbow tendinopathies, it is necessary to explore possible treatments and evaluate the strength of evidence to guide health professionals. With the recent emergence of PRP injections for elbow tendinopathies, it is important to assess its efficacy, safety, and cost effectiveness, especially considering many insurance companies do not cover this procedure, and consider whether further research is warranted.

\section{Objective}

The aim of this review was to systematically evaluate the evidence regarding the effect and safety of platelet-rich plasma injections for elbow tendinopathies.

\section{METHODS}

\section{Criteria for Considering Studies for this Review Types of Studies}

This systematic review included only quantitative, prospective studies from peer-reviewed journals. Both clinical trials and cohort studies that had a comparator group were included. Cohort studies were included because of the paucity of clinical trials on the topic; however, limiting the review to comparison studies adds validity to the meta-analysis. Under the NHMRC Evidence Hierarchy therefore, this equated to Level II and Level III evidence. ${ }^{18}$ The meta-analysis focused on studies published in the English language. 


\section{Types of Participants}

Trials were included if they reported subjects with tendinopathies present in either the lateral or medial elbow. Due to the wideranging terminology used in the literature, descriptions of tendinopathy, tendinitis, tendinosis, epicondylitis, epicondylagia, epicondylosis, tennis elbow, and golfer's elbow were all considered in the review. Trials that included subjects with tendon ruptures or post-surgical tendon repairs were excluded. No restrictions were made on subjects' age or gender.

\section{Types of Intervention}

Studies were considered if they reported PRP as one of the interventions being investigated for elbow tendinopathies, regardless of how many PRP injections were administered. No restrictions were imposed on the type of comparator (eg. corticosteroid, whole blood) in order to examine the effectiveness of PRP against many existing interventions.

\section{Types of Outcomes}

All studies were required to have an outcome measure for pain or self-reported function, as pain and loss of function are the primary complaints of patients with elbow tendinopathy. No restrictions were placed on how these outcomes should be measured. The presence of adverse outcomes was of interest, but did not form part of the eligibility criteria.

\section{Search Methods for Identification of Studies}

The following databases were searched for relevant studies: Medline, Embase, CINAHL, Cochrane, PubMed and SportsDiscus. A list of key search terms, grouped into three key concepts, was utilised for literature searching. These three concepts were combined to capture the most relevant studies.

Concept one: platelet-rich plasma; Concept two: tendinopath* or tendinitis or tendinosis or epicondyl*; Concept three: elbow. The search was limited (where available) to studies involving humans and those published in the English Language. The reference lists of included articles were examined for additional studies that may not have been indexed in the electronic databases.

\section{Data Collection and Analysis \\ Selection of Studies}

The titles and abstracts retrieved from the search were examined for relevance. Potentially relevant articles were then obtained in full text and independently assessed for eligibility.

\section{Assessment of Bias in Included Studies}

The McMaster Critical Review Form was chosen for critical appraisal, as it is suitable for most types of studies. ${ }^{19}$ However, as randomized controlled trials (RCTs) were also included in the review, additional criteria to assess validity were added for these studies. Additional criteria were not included in total and percentage scores for non-RCT studies. Critical appraisal was undertaken independently; any disagreements were resolved by discussion and mutual consensus.

\section{Data Extraction and Synthesis}

The reviewers extracted key data in the areas of subject characteristics (gender, age, duration of symptoms), intervention/comparator intervention given, outcome measures, and results. P-values and confidence intervals were gathered where available to determine significance of the results. Given the heterogeneity of studies, a narrative approach was deemed as an appropriate method to synthesise the findings of individual studies. Data from individual studies were organised according to the outcomes identified in the criteria for considering studies.

\section{RESULTS \\ Description of Studies \\ Results of the Search}

Electronic database searching retrieved 299 journal articles related to platelet-rich plasma or elbow tendinopathies. After removing duplicates, this was reduced to 157 . After screening, 10 articles were identified as being potentially eligible and were assessed in full-text. An overview of the search results is provided in Figure 1. 


\section{Figure 1. Consort Diagram}

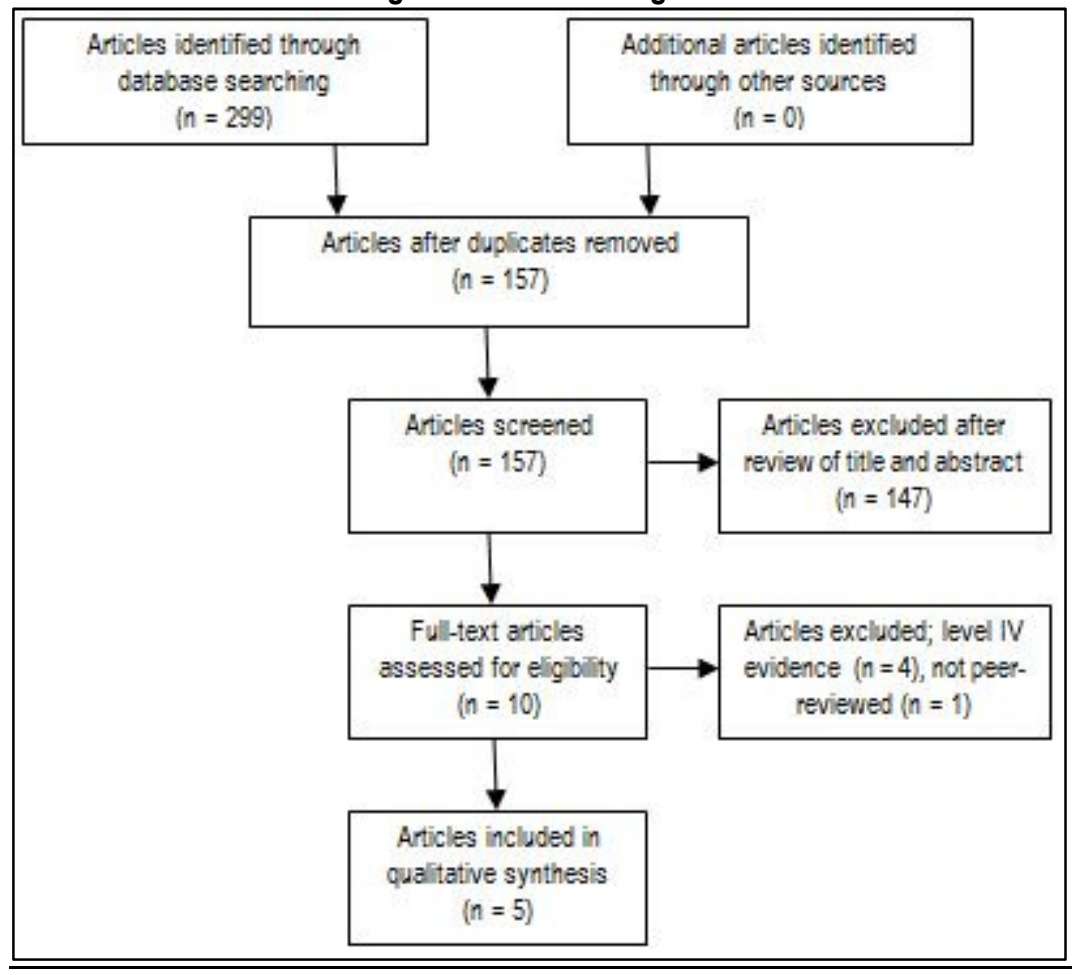

\section{Included Studies}

Five studies met the inclusion criteria: four RCTs and one cohort study. The characteristics of the participants are given in Table 1 and the nature of the interventions and outcomes are given in Table 2. The study by Gosens et al is a two-year follow-up from the study by Peerbooms et al. 20,21

Table 1. Characteristics of the Participants

\begin{tabular}{|c|c|c|c|c|}
\hline Study & Sample size & Mean age (years) & Gender & $\begin{array}{l}\text { Mean symptom } \\
\text { duration (months) }\end{array}$ \\
\hline $\begin{array}{l}\text { Creaney et al. } \\
2011^{22}\end{array}$ & $\begin{array}{l}\text { PRP: } 80 \\
\text { Blood: } 70\end{array}$ & $\begin{array}{l}\text { PRP: } 53 \\
\text { Blood: } 48\end{array}$ & $\begin{array}{l}\text { Given as } \\
\text { percentages: } \\
\text { PRP: } 57 \% \mathrm{M} \\
\text { Blood: } 56 \% \mathrm{M}\end{array}$ & $\begin{array}{l}\text { Not reported } \\
\text { (however inclusion } \\
\text { criteria stated } \\
\text { duration }>6 \\
\text { months) }\end{array}$ \\
\hline $\begin{array}{l}\text { Mishra \& Pavelko } \\
2006^{3}\end{array}$ & $\begin{array}{l}\text { PRP:15 } \\
\text { Control: } 5\end{array}$ & $\begin{array}{l}\text { PRP: } 48.1 \\
\text { Control: } 42.2\end{array}$ & Not reported & $\begin{array}{l}\text { PRP: } 15.3 \\
\text { Control: } 11.8\end{array}$ \\
\hline $\begin{array}{l}\text { Peerbooms et al. } \\
2010^{21} \\
\text { Gosens et al. } 2011^{20}\end{array}$ & $\begin{array}{l}\text { Corticosteroid: } 51 \\
\text { PRP: } 49\end{array}$ & $\begin{array}{l}\text { Corticosteroid: } 47.3 \\
\text { PRP: } 46.9\end{array}$ & $\begin{array}{l}F=52 \\
M=48\end{array}$ & $\begin{array}{l}\text { Not reported } \\
\text { (however inclusion } \\
\text { criteria stated } \\
\text { duration }>6 \\
\text { months) }\end{array}$ \\
\hline $\begin{array}{l}\text { Thanasas et al. } \\
2011^{23}\end{array}$ & $\begin{array}{l}\text { Blood: } 14 \\
\text { PRP: } 14\end{array}$ & $\begin{array}{l}\text { Blood: } 36.6 \\
\text { PRP: } 35.9\end{array}$ & $\begin{array}{l}F=24 \\
M=4\end{array}$ & $\begin{array}{l}\text { Blood: } 5.1 \\
\text { PRP: } 4.7\end{array}$ \\
\hline
\end{tabular}

PRP: platelet-rich plasma, F: female, M: male 
Table 2. Nature of the Interventions and Outcomes

\begin{tabular}{|c|c|c|c|c|}
\hline Study & Interventions & Co-interventions & Outcomes & Follow-up periods \\
\hline $\begin{array}{l}\text { Creaney et al. } \\
2011^{22}\end{array}$ & $\begin{array}{l}\text { PRP: } 2 \text { injections of } \\
\text { PRP ( } 0 \text { months and } \\
1 \text { month) } \\
\text { Blood: } 2 \text { injections } \\
\text { of whole blood ( } 0 \\
\text { months and } 1 \\
\text { month) }\end{array}$ & Nil & PRTEE & $\begin{array}{l}1 \text { month } \\
3 \text { months } \\
6 \text { months }\end{array}$ \\
\hline $\begin{array}{l}\text { Mishra \& Pavelko } \\
2006^{3}\end{array}$ & $\begin{array}{l}\text { PRP: } 1 \text { injection of } \\
2-3 \mathrm{~mL} \text { of PRP } \\
\text { Control: } 1 \text { injection } \\
\text { of } 2-3 \mathrm{~mL} \\
\text { bupivacaine with } \\
\text { epinephrine }\end{array}$ & $\begin{array}{l}\text { Both groups given } \\
\text { standardized } \\
\text { stretching for } 2 \\
\text { weeks, followed by } \\
\text { a strengthening } \\
\text { program (duration } \\
\text { not specified) }\end{array}$ & $\begin{array}{l}\text { Pain (VAS) } \\
\text { Modified Mayo } \\
\text { elbow score }\end{array}$ & $\begin{array}{l}4 \text { weeks } \\
8 \text { weeks } \\
6 \text { months }\end{array}$ \\
\hline $\begin{array}{l}\text { Peerbooms et al. } \\
2010^{21}\end{array}$ & \multirow{2}{*}{$\begin{array}{l}\text { Corticosteroid: } 1 \\
\text { injection of } 1 \mathrm{~mL} \text { of } \\
\text { corticosteroid with } \\
\text { bupivacaine and } \\
\text { epinephrine } \\
\text { PRP: } 1 \text { injection of } \\
1 \mathrm{~mL} \text { of PRP } \\
{ }^{* *} \text { Re-intervention } \\
\text { was allowed if } \\
\text { needed }\end{array}$} & \multirow{2}{*}{$\begin{array}{l}\text { Both groups given } \\
\text { standardized } \\
\text { stretching for } 2 \\
\text { weeks, followed by } \\
\text { a strengthening } \\
\text { program (duration } \\
\text { not specified) }\end{array}$} & \multirow[t]{2}{*}{$\begin{array}{l}\text { Pain (VAS) } \\
\text { DASH }\end{array}$} & $\begin{array}{l}4 \text { weeks } \\
8 \text { weeks } \\
12 \text { weeks } \\
26 \text { weeks } \\
52 \text { weeks }\end{array}$ \\
\hline $\begin{array}{l}\text { Gosens et al. } \\
2011^{20}\end{array}$ & & & & 104 weeks \\
\hline $\begin{array}{l}\text { Thanasas et al. } \\
2011^{23}\end{array}$ & $\begin{array}{l}\text { Blood: } 1 \text { injection of } \\
3 \mathrm{~mL} \text { of whole blood } \\
\text { PRP: } 1 \text { injection of } \\
3 \mathrm{~mL} \text { of PRP }\end{array}$ & $\begin{array}{l}\text { Both groups given } \\
\text { simple stretching } \\
\text { and eccentric } \\
\text { exercises to do } \\
\text { individually, twice } \\
\text { daily for } 5 \text { weeks }\end{array}$ & $\begin{array}{l}\text { Pain (VAS) } \\
\text { Liverpool Elbow } \\
\text { Score }\end{array}$ & $\begin{array}{l}6 \text { weeks } \\
3 \text { months } \\
6 \text { months }\end{array}$ \\
\hline
\end{tabular}

PRP: platelet-rich plasma, VAS: visual analogue scale, PRTEE: patient rated tennis elbow evaluation, DASH: Disabilities of the arm, shoulder and hand.

\section{Risk of Bias in Included Studies}

Critical appraisal scores for the included studies are displayed in Table 3. The article by Gosens et al was not critically appraised separately as it was the follow-up to the Peerbooms et al study. ${ }^{20,21}$ Two studies did not describe their sample adequately and one study did not provide a power calculation or other explanation to justify their sample size.3,22 Four out of five studies did not describe the reliability and validity of the outcome measures they had used. ${ }^{20-23}$ The RCTs all allocated their subjects randomly; however, none blinded the therapist and some did not blind the subjects or the assessors. ${ }^{20-23}$ Additionally, one study administered two PRP injections and the other studies only administered one..$^{22}$ The duration of symptoms across studies was not consistent but was at least three months in each study. 
Table 3. Critical Appraisal

\begin{tabular}{|c|c|c|c|c|}
\hline & $\begin{array}{l}\text { Creaney et al } \\
2011^{22}\end{array}$ & $\begin{array}{l}\text { Mishra \& } \\
\text { Pavelko 20063 }\end{array}$ & $\begin{array}{l}\text { Peerbooms et al } \\
2010^{21} \& \\
\text { Gosens et al } \\
2011^{20}\end{array}$ & $\begin{array}{l}\text { Thanasas et al } \\
2011^{23}\end{array}$ \\
\hline NHMRC Level of evidence ${ }^{18}$ & Level II & Level III-2 & Level II & Level II \\
\hline \multicolumn{5}{|l|}{ McMaster Criteria ${ }^{19}$} \\
\hline Clear study purpose & 1 & 1 & 1 & 1 \\
\hline $\begin{array}{l}\text { Relevant background literature } \\
\text { reviewed }\end{array}$ & 1 & 1 & 1 & 1 \\
\hline Specify design & RCT & Cohort & RCT & RCT \\
\hline Sample described in detail & 0 & 0 & 1 & 1 \\
\hline Sample size justified & 1 & 0 & 1 & 1 \\
\hline Reliable outcome measures & 0 & 1 & 0 & 0 \\
\hline Valid outcome measures & 1 & 1 & 0 & 0 \\
\hline Interventions described in detail & 1 & 1 & 1 & 1 \\
\hline Contamination avoided & 1 & 1 & 1 & 1 \\
\hline Cointervention avoided & 1 & 1 & 1 & 1 \\
\hline $\begin{array}{l}\text { Results reported in terms of statistical } \\
\text { significance }\end{array}$ & 1 & 1 & 1 & 1 \\
\hline Appropriate analysis methods & 1 & 1 & 1 & 1 \\
\hline Clinical importance reported & 1 & 1 & 1 & 0 \\
\hline Drop-outs reported & 1 & 1 & 1 & 1 \\
\hline Appropriate conclusions & 1 & 1 & 1 & 1 \\
\hline \multicolumn{5}{|l|}{ Additional RCT criteria } \\
\hline Random allocation of subjects & 1 & NA & 1 & 1 \\
\hline Blinding of subjects & 0 & NA & 1 & 0 \\
\hline Blinding of therapist & 0 & NA & 0 & 0 \\
\hline Blinding of assessors & 0 & NA & 0 & 1 \\
\hline TOTAL SCORE & 13 & 12 & 14 & 13 \\
\hline TOTAL \% & $72 \%$ & $86 \%$ & $78 \%$ & $72 \%$ \\
\hline
\end{tabular}

RCT: randomized controlled trial, NA: not applicable

\section{Effects of Interventions}

A quantitative synthesis of findings was not possible because of the heterogeneity of variables (i.e., intervention dosage and frequency) and outcomes examined by individual studies. Thus, findings are presented in a narrative summary. The use of confidence intervals and $p$ values to report on the significance of the data was variable through the studies. None of the studies reported on effect size.

\section{Pain}

Four studies used the Visual Analogue Scale (VAS), using pain reduction as a measure of efficacy. Mishra and Pavelko found that there was a significant reduction in pain in the PRP group at four weeks and eight weeks compared with the control group. ${ }^{3}$ By the next follow-up period at six months, 3 out of 5 controls had dropped out, thus the PRP group could not be compared to the controls. However, the six month follow-up of the PRP group showed a significant difference in pain from baseline. ${ }^{3}$ Thanasas and colleagues' results showed that both the PRP and whole blood groups had improvements in pain at 6 weeks, 3 months, and 6 months. ${ }^{23}$ The PRP group had lower pain scores than the whole blood group at each re-evaluation interval; however, the difference was only significant at 6 weeks..$^{23}$

According to the Peerboom et al trial, after four weeks, the corticosteroid group's pain worsened whereas the PRP group continued to slowly improve; the PRP group had significantly less pain than the corticosteroid group at both 26 weeks and 52 weeks. ${ }^{21}$ This was maintained in the two-year follow-up study by Gosens et al, which showed significantly less pain in the PRP group at 104 weeks post-injection. ${ }^{20}$ 


\section{Physical Function}

While only four studies used the VAS to evaluate pain as an outcome measure, all studies also used some kind of outcome measure for physical function; however, the measures used varied across studies, which makes comparison between studies somewhat difficult.

Mishra and Pavelko used a modified Mayo elbow score, a measure of elbow pain, motion, stability, and function, and found there was greater improvement in the PRP group compared with controls at both 4 and 8 weeks, but this was statistically significant only at 8 weeks. As with the pain measure, analysis between groups at 6 months could not be completed because of the high drop-out rate of controls. At 6 months however, the PRP group maintained a statistically significant improvement in their Mayo elbow score from baseline. ${ }^{3}$

Thanasas et al and Creaney et al compared whole blood with PRP in terms of physical function outcomes using the Liverpool elbow score and the Patient Rated Tennis Elbow Evaluation (PRTEE) respectively.22,23 Thanasas et al found no significant difference at any time points between the whole blood and PRP groups in terms of physical function; however, both groups did improve. ${ }^{23}$ Creaney et al reported both the blood and PRP groups improved at 3 months, with no significant difference between groups. At 6 months, the blood group showed greater improvements than the plasma group. However, the authors excluded subjects who elected to have surgery in their analysis, a greater proportion of which were in the blood group. As the authors themselves reported, this falsely creates an impression of greater improvement in the blood group. As a result, these findings should be interpreted with caution. 22

Peerbooms et al used the Disabilities of the Arm, Shoulder and Hand (DASH) score to assess physical function. They found a similar trend in changes of physical function to that of pain, whereby the corticosteroid group initially improved more, then worsened, whereas the PRP group had a gradual improvement. There were no significant differences in the DASH scores between the corticosteroid group and the PRP group until 26 weeks, when the PRP group was significantly better. This difference was maintained at 52 weeks and again at 104 weeks in the follow-up study by Gosens et al. ${ }^{20,21}$

\section{Adverse Effects}

Only three of the studies reported on adverse effects. Thanasas and colleagues reported several subjects (9 of PRP group and 4 of whole blood group) had short-term local pain at the injection site. There were no other complications. ${ }^{23}$ Peerbooms and colleagues reported, as did Gosens et al in the follow-up, that there were no systemic reactions, fevers, or rashes. They did, however, discuss that local inflammation had caused an initial worsening of pain after the injection, but did not report the number of subjects who experienced the symptoms nor their group assignments. ${ }^{20,21}$

\section{DISCUSSION}

The aim of this review was to systematically review the evidence regarding the effect and safety of platelet-rich plasma injections for elbow tendinopathies. The evidence suggests that PRP does improve both pain and physical function in chronic elbow tendinopathies; however, its efficacy compared with corticosteroid and autologous blood injections was variable. Overall, there is insufficient evidence to support PRP as a first line treatment for chronic elbow tendinopathies. There is some evidence to suggest that when considering injection therapy, PRP should be trialed before a cortisone injection and may be equally as effective as whole blood. The two studies that reported regarding safety and adverse effects found that PRP was a safe intervention with no significant adverse effects, although it could be argued that the cost effectiveness of PRP injections is significantly higher than other conservative methods of treatment for elbow tendinopathies.

In the studies reviewed, all subjects had a symptom duration of at least 3 months and had not responded to other conservative management. Thus, the results can be applied to patients with chronic elbow tendinopathies, but does not provide any indication regarding the usefulness of PRP injections in patients with acute onset of elbow tendinopathies or as an initial treatment.

Several limitations to the current review exist due to the heterogeneity of the available studies regarding PRP and elbow tendinopathies. The PRP intervention was not prepared and delivered in a standard manner, and the volume and frequency of PRP injections varied across the studies. The activation of PRP and platelet growth factor release, or bioactivity, is significantly affected by the different platelet harvesting methods used.24,25 Specifically, the concentration of platelets and presence or absence of leukocytes in the PRP treatment may play alter the PRP's effectiveness. ${ }^{3}$ Sampson et al suggest that this lack of standardisation of PRP preparation protocols may theoretically affect data, presenting a limitation to the current findings. ${ }^{12}$ Variations also existed in the exercise co-interventions between studies and the detail of their description. While Thanasas and colleagues reported that a standard rehabilitation program of stretching and eccentric loading exercises was given and indicated the prescribed frequency, no other details of the exercise prescription were given. ${ }^{23}$ Mishra and Pavelko and Peerbooms et al

(c) The Internet Journal of Allied Health Sciences and Practice, 2013 
both initiated a two week stretching protocol and then formal strengthening program; however, the authors did not detail the specifics of the exercise prescription. 3,21 Creaney et al did not state any rehabilitation program at all.22 This lack of standardized rehabilitation protocol could potentially have contributed to the mixed results observed between studies. Additionally, the lack of detail regarding exercise prescription within the current PRP research limits the utility of the intervention in clinical practice.

It could be argued that the use of the Liverpool Elbow Score to measure physical function by Thanasas et al was inappropriate, as this takes into account elbow ROM and the ulnar nerve, both of which are not usually affected in lateral elbow epicondylosis. ${ }^{23}$ This may, therefore, have impacted on the lack of a significant difference between the PRP and whole blood groups in this study. The different choices of outcome measures for physical function between studies certainly limited the ability to synthesise the results and draw conclusions.

At an individual level within the studies, some methodological flaws existed. Two studies had particularly small sample sizes, and the level of blinding in the RCTs was inadequate. The cohort study has limitations in its results based upon the study design, and thus lack of blinding or randomization. The statistical analyses conducted did not consistently present $p$-values for statistical significance or confidence intervals, and no study reported on effect sizes.

\section{CONCLUSIONS}

\section{Implications for Practice}

The implication of the limitations of the available literature is that it is difficult to determine how much of an effect PRP has on elbow tendinopathies, and it is not possible to make recommendations regarding a standard process of PRP preparation and prescription to achieve the best outcomes.

There is insufficient evidence to recommend the use of PRP injections over other modalities for the treatment of elbow tendonopathies. However, this review has demonstrated that there is enough evidence to suggest the use of PRP may be beneficial for both pain and physical function within presentations of chronic elbow tendinopathies, especially those longer than 3 months duration. This review has also demonstrated that PRP injections should be trialed before corticosteroid injections and that PRP injections provide another conservative treatment approach that can be trialed before surgery.

\section{Implications for Research}

Further randomised controlled trials investigating the efficacy of PRP injections versus whole blood, cortisone injections, or any other modality, or one injection versus multiple injections, for elbow tendonopathies are required before this treatment can be routinely recommended. Further research should also investigate PRP injections versus a placebo. It would be of benefit if future research was conducted with greater sample sizes of more specific populations, greater randomization, and a standard preparation of the PRP. Both pain and physical function, inclusive of level of difficulty with functional activities, should be measured with the use of appropriate outcome measures and a clearly defined rehabilitation program within each trial.

\section{ACKNOWLEDGEMENT}

We would like to thank Lucylynn Lizarondo for her assistance and mentorship throughout the preparation of the manuscript.

\section{REFERENCES}

1. Green S, Buchbinder R, Barnsley L, Hall S, White M, Smidt N, Assendelft WJJ. Acupuncture for lateral elbow pain. Cochrane Database of Systematic Reviews. 2008; art. no. CD003527, DOI: 10.1002/14651858.CD003527. [PMID 11869671]

2. Buchbinder R, Johnston RV, Barnsley L, Assendelft WJJ, Bell SN, Smidt N. Surgery for lateral elbow pain. Cochrane Database of Systematic Reviews. 2011; art. no. CD003525, DOI: 10.1002/14651858.CD003525.pub2. [PMID 21412883]

3. Mishra A, Pavelko P. Treatment of Chronic Elbow Tendinosis With Buffered Platelet-Rich Plasma. The American Journal of Sports Medicine. 2006;34(11):1774-8. [PMID 16735582]

4. Walker-Bone K, Palmer K, Reading I, Coggon D, Cooper C. Prevalence and impact of musculoskeletal disorders of the upper limb in the general population. Arthritis Care \& Research. 2004;51(4):642-51. [PMID 15334439]

5. Smidt N, van der Windt D, Assendelft W, Deville W, Korthals-de Bos I, Bouter I. Corticosteroid injections, physiotherapy, or a wait-and-see policy for lateral epicondylitis: a randomised controlled trial. The Lancet. 2002;359(9307):657-62. [PMID 11879861]

6. Stastinopoulos D, Stasinopoulou K, Johnson M. An exercise programme for the management of lateral elbow tendinopathy. British Journal of Sports Medicine. 2005;39(12):944-7. [PMID 16306504]

7. Malliaras $\mathrm{P}$, Maffulli N, Garau G. Eccentric training programmes in the management of lateral elbow tendinopathy. Disability and Rehabilitation. 2008;30(20-22):1590-6. [PMID 18608381] 
8. Green S, Buchbinder R, Barnsley L, Hall S, White M, Smidt N, Assendelft WJJ. Non-steroidal anti-inflammatory drugs (NSAIDs) for treating lateral elbow pain in adults. Cochrane Database of Systematic Reviews. 2009; art. no. CD003686. DOI: 10.1002/14651858.CD003686. [PMID 12076503]

9. Bjordal J, Lopes Martins R, Joensen J, Couppe C, Ljunggren A, Stergioulas A, Johnson M. A systematic review with procedural assessments and meta-analysis of Low Level Laser Therapy in lateral elbow tendinopathy (tennis elbow). BMC Musculoskeletal Disorders. 2008;9(75). [PMID 18510742]

10. Rompe J, Maffulli N. Repetitive shock wave therapy for lateral elbow tendinopathy (tennis elbow): a systematic and qualitative analysis. British Medical Bulletin. 2007;83(1):355-78. [PMID 17626054]

11. Coombes B, Bisset L, Vincenzino B. Efficacy and safety of corticosteroid injections and other injections for management of tendinopathy: a systematic review of randomised controlled trials. The Lancet. 2010;376(9754):1751-67. [PMID 20970844]

12. Sampson S, Gerhardt M, Mandelbaum B. Platelet rich plasma injection grafts for musculoskeletal injuries: a review. Current Reviews in Musculoskeletal Medicine. 2008;1(3):165-74 [PMID 19468902]

13. Dohan Ehrenfest D, Ramusson L, Albreksson T. Classification of platelet concentrates: from pure platelet-rich plasma (PPRP) to leucocyte- and platelet-rich fibrin (L-PRF), Trends in Biotechnology. 2009;27(3):158-67 [PMID 19187989]

14. de Vos R, van Veldhoven P, Moen M, Tol J, Maffulli N. Autologous growth factor injections in chronic tendinopathy: a systematic review. British Medical Bulletin. 2010;95(1);63-77. [PMID 20197290]

15. Kampa $R$, Connell $D$. Treatment of tendinopathy: is there a role of autologous whole blood and platelet rich plasma injection? The International Journal of Clinical Practice. 2010;64(13):1813-23. [PMID 21070532]

16. Taylor D, Petrera M, Hendry M, Theodoropoulos J. A systematic review of the use of platelet-rich plasma in sports medicine as a new treatment for tendon and ligament injuries. Clinical Journal of Sports Medicine. 2011;21(4):344-52. [PMID 21562414]

17. Rabago D, Best T, Zgierska A, Zeisig E, Ryan M, Crane D. A systematic review of four injection therapies for lateral epicondylosis: prolotherapy, polidocanol, whole blood and platelet-rich plasma. British Journal of Sports Medicine. 2009;43(7):471-81. [PMID 19028733]

18. Merlin T, Weston A, Tooher R. Extending an evidence hierarchy to include topics other than treatment: revising the Australian 'levels of evidence'. BMC Medical Research Methodology. 2009;9(34). [PMID 19519887]

19. Law M, Stewart D, Pollock N, Letts, L, Bosch, J, Wesmorland, M. Critical review form - Quantitative studies. McMaster University: Occupational Therapy Evidence-Based Practice Research Group. 1998.

20. Gosens T, Peerbooms J, van Laar W, den Oudsten B. Ongoing positive effect of platelet-rich plasma versus corticosteroid injection in lateral epicondylitis: a double-blind randomized controlled trial with 2-year follow-up. The American Journal of Sports Medicine. 2011;39(6):1200-8. [PMID 21422467]

21. Peerbooms J, Sluimer J, Bruijn D, Gosens T. Positive effect of an autologous platelet concentrate in lateral epicondylitis in a double-blind randomized controlled trial: platelet-rich plasma versus corticosteroid injection with a 1-year follow-up. The American Journal of Sports Medicine. 2010;38(2):255-62. [PMID 20448192]

22. Creaney L, Wallace A, Curtis M, Connell D. Growth factor-based therapies provide additional benefit beyond physical therapy in resistant elbow tendinopathy: a prospective, single-blind, randomized trial of autologous blood injections versus platelet-rich plasma. British Journal of Sports Medicine. 2011;45(12):966-71. [PMID 21406450]

23. Thanasas C, Papadimitriou G, Charalambidis C, Paraskevopoulos I, Papanikolaou A. Platelet-rich plasma versus autologous blood for the treatment for chronic lateral elbow epicondylitis: a randomized controlled clinical trial. The American Journal of Sports Medicine. 2011;39(10):2130-4. [PMID 21813443]

24. Mishra A, Gosens T. Clinical Indications and Techniques for the Use of Platelet-Rich Plasma in the Elbow. Operative Techniques in Sports Medicine. 2011;19(3):170-6.

25. Everts P, Brown-Mahoney C, Hoffmann J, Schönberger J, Box H, van Zundert A, Knape J. Platelet rich plasma preparation using three devices. Implications on platelet activation and platelet growth factor release. Growth Factors. 2006;24(3):16571. [PMID 17079200] 